\title{
Anterior Cranial Base Reconstruction with a Reverse Temporalis Muscle Flap and Calvarial Bone Graft
}

\author{
Seung Gee Kwon, Yong Oock Kim, Dong Kyun Rah \\ Institute of Human Tissue Restoration, Department of Plastic and Reconstructive Surgery, Yonsei University Health System, Severance \\ Hospital, Yonsei University College of Medicine, Seoul, Korea
}

Background Cranial base defects are challenging to reconstruct without serious complications. Although free tissue transfer has been used widely and efficiently, it still has the limitation of requiring a long operation time along with the burden of microanastomosis and donor site morbidity. We propose using a reverse temporalis muscle flap and calvarial bone graft as an alternative option to a free flap for anterior cranial base reconstruction.

Methods Between April 2009 and February 2012, cranial base reconstructions using an autologous calvarial split bone graft combined with a reverse temporalis muscle flap were performed in five patients. Medical records were retrospectively analyzed and postoperative computed tomography scans, magnetic resonance imaging, and angiography findings were examined to evaluate graft survival and flap viability.

Results The mean follow-up period was 11.8 months and the mean operation time for reconstruction was $8.4 \pm 3.36$ hours. The defects involved the anterior cranial base, including the orbital roof and the frontal and ethmoidal sinus. All reconstructions were successful. Viable flap vascularity and bone survival were observed. There were no serious complications except for acceptable donor site depressions, which were easily corrected with minor procedures.

Conclusions The reverse temporalis muscle flap could provide sufficient bulkiness to fill dead space and sufficient vascularity to endure infection. The calvarial bone graft provides a rigid framework, which is critical for maintaining the cranial base structure. Combined anterior cranial base reconstruction with a reverse temporalis muscle flap and calvarial bone graft could be a viable alternative to free tissue transfer.

Keywords Bone transplantation / Skull base / Surgical flaps
Correspondence: Yong Oock Kim Department of Plastic and Reconstructive Surgery, Yonsei University Health System, Severance Hospital, Yonsei University College of Medicine, 50 Yonsei-ro, Seodaemun-gu, Seoul 120-752, Korea Tel: +82-2-2228-2218

Fax: +82-2-393-6947

E-mail: sgm625@yuhs.ac

This article was presented at the 2 nd Research and Reconstruction Forum on June 1-2, 2012 in Gwangju, Korea.

No potential conflict of interest relevant to this article was reported.

Received: 5 Apr 2012 • Revised: 16 May 2012 • Accepted: 22 May 2012

pISSN: 2234-6163・ elSSN: 2234-6171 • http://dx.doi.org/10.5999/aps.2012.39.4.345・Arch Plast Surg 2012;39:345-351

\section{INTRODUCTION}

Cranial base defects due to trauma or tumor removal surgery should be covered to prevent communication between intraand extra-cranial spaces. Although it is crucial to separate these spaces to prevent potentially significant complications such as cerebrospinal fluid (CSF) leakage, which could result in chronic meningitis and encephalitis, or the break-down of structural integrity, which could result in a meningocele or encephalocele, there is no gold standard approach for covering large anterior

Copyright $(\odot) 2012$ The Korean Society of Plastic and Reconstructive Surgeons

This is an Open Access article distributed under the terms of the Creative Commons Attribution Non-Commercial License (http://creativecommons.org/

licenses/by-nc/3.0/) which permits unrestricted non-commercial use, distribution, and reproduction in any medium, provided the original work is properly cited.

www.e-aps.org 
cranial base defects [1-5].

A variety of approaches have been used to cover large anterior skull base defects. However, local flaps such as galeal, pericranial, and fascial flaps do not have sufficient volume or size to fill defects with a large amount of dead space, and sometimes they are unavailable due to adjacent infection or direct trauma to the soft tissue near the lesion. The fat graft is not appropriate for large defects because of its resorptive character and poor vascularity. The use of a conventional temporalis muscle flap is limited in that the flap length is insufficient to reach to the mid-portion of the anterior cranial base and it is not sufficiently bulky or vascular at the distal end. Bone grafts are not sufficient to create a watertight closure and bone substitutes have limitations such as the potential for infection and high costs $[2,6]$. Therefore, as an improved microsurgical technique, free tissue transfer has been considered the best option for wide cranial defects and has a low complication rate [3,7-10]. However, microanastomosis, the requirement of two operation fields, donor site morbidity, and the possibility of flap failure are still a burden to both surgeons and patients, even if the risk is considered acceptably low.

In this study, we reconstructed large anterior cranial base defects by successfully combining an autologous calvarial split bone graft and reverse temporalis muscle flap using retrograde blood flow from the superficial temporal artery to the deep temporal artery. Therefore, we suggest that a reverse temporalis muscle flap with a calvarial bone graft, which only requires one operation field, is a suitable and versatile surgical technique for overcoming the limitations of conventional reconstruction options for large anterior and inner cranial base defects.

\section{METHODS}

Five patients who underwent anterior skull base reconstruction with reverse temporalis muscle flap transposition and split calvarial bone grafting from April 2009 to February 2012 were enrolled (Table 1). A retrospective chart and radiologic image review of these patients was performed. The characteristics of the defects, operation time, and length of neurosurgery intensive care unit (NICU) stay were evaluated. The size of the flap and types (uni- or bilateral) were also reviewed. Computed tomography (CT), magnetic resonance imaging (MRI), and $\mathrm{CT}$ angiography or conventional angiography were performed to evaluate postoperative results and flap stability. The ages of the three male and two female patients included in this study ranged from 10 to 65 years.

\section{Surgical technique}

A bicoronal scalp incision was made and the anterior scalp flap was elevated in the subpericranial layer. Additionally, a subfollicular flap was elevated in the temporal area to preserve the superficial temporal vessels. About $2 \mathrm{~cm}$ above the temporal crest, the pericranium was incised and the temporal muscle was elevated gently to the zygomatic arch (Fig. 1A). A continuous running suture with absorbable suture material was applied along the origin of the temporalis muscle to prevent unwanted total separation of the temporalis muscle from the superficial temporal fascia layer [6]. After tumor removal or debridement, the defect size was measured. Defect sizes ranged from a maximum of $68 \times 31 \mathrm{~mm}$ to a minimum of $24 \times 47 \mathrm{~mm}$.

\begin{tabular}{|c|c|c|c|c|c|c|c|c|c|c|c|}
\hline Patient & $\begin{array}{c}\text { Follow- } \\
\text { up })^{\text {a) }} \\
(\mathrm{mo})\end{array}$ & Age & Sex & Diagnosis & Defect site & $\begin{array}{l}\text { Defect } \\
\text { size })^{\text {b) }} \\
(\mathrm{mm})\end{array}$ & $\begin{array}{l}\text { RTMF } \\
\text { eleva- } \\
\text { tion }\end{array}$ & $\begin{array}{l}\text { Flap } \\
\text { size } \\
(\mathrm{cm})\end{array}$ & $\begin{array}{l}\text { Graft } \\
\text { size } \\
(\mathrm{cm})\end{array}$ & $\begin{array}{l}\text { OP } \\
\text { time } \\
(\mathrm{hr})\end{array}$ & $\begin{array}{l}\text { NICU } \\
\text { stay } \\
\text { (day) }\end{array}$ \\
\hline 1 & 24 & 65 & M & Mucocele & $\begin{array}{l}\text { Anterior cranial base to } \\
\text { ethmoidal \& frontal sinus, } \\
\text { left. orbital roof }\end{array}$ & $68 \times 31$ & Unilateral & $12 \times 4$ & $\begin{array}{l}2 \times 4 \\
7 \times 3 \\
2 \times 3\end{array}$ & 6 & 1 \\
\hline 2 & 23 & 19 & $\mathrm{~F}$ & Fibrous dysplasia & $\begin{array}{l}\text { Anterior cranial base to } \\
\text { ethmoidal \& frontal sinus, } \\
\text { right. orbital roof \& medial } \\
\text { orbital wall }\end{array}$ & $55 \times 38$ & Unilateral & $20 \times 8$ & $\begin{array}{l}6 \times 4 \\
8 \times 4\end{array}$ & 13 & 2 \\
\hline 3 & 2 & 15 & M & $\begin{array}{l}\text { Recurrent meningitis } \\
\text { with CSF leakage }\end{array}$ & $\begin{array}{l}\text { Anterior cranial base to } \\
\text { ethmoidal sinus \& frontal } \\
\text { sinus }\end{array}$ & $43 \times 29$ & Bilateral & $15 \times 6$ & $\begin{array}{l}4 \times 3 \\
\text { (Mimix } \\
\text { paste) }\end{array}$ & 11 & 1 \\
\hline 4 & 9 & 10 & M & $\begin{array}{l}\text { Encephalocele with } \\
\text { meningitis }\end{array}$ & $\begin{array}{l}\text { Anterior cranial base to } \\
\text { ethmoidal sinus \& frontal } \\
\text { sinus }\end{array}$ & $24 \times 47$ & Bilateral & $12 \times 6$ & $\begin{array}{c}1 \times 3 \\
\text { (4 pieces) }\end{array}$ & 6 & 1 \\
\hline 5 & 1 & 12 & $\mathrm{~F}$ & Myxofibrosarcoma & $\begin{array}{l}\text { Anterior cranial base, left. } \\
\text { orbital roof }\end{array}$ & $52 \times 41$ & Unilateral & $12 \times 5$ & $6 \times 5$ & 6 & 1 \\
\hline Average & $11.8 \pm 11.12$ & $24.2 \pm 23.06$ & & & & & & & & $8.4 \pm 3.36$ & $1.2 \pm 0.45$ \\
\hline
\end{tabular}


The split calvarial bone was designed in one piece or several pieces according to the curvature and size of the defect (Fig. 1B). Calvarial bone was harvested from a craniotomized frontal bone flap, which was elevated to approach the anterior skull base. In patient 3, hydroxyapatite cement (Mimix, W. Lorenz Surgical, Jacksonville, FL, USA) was used instead of an autologous bone graft. The frontal bone flap was too thin to be split and was not healthy because of recurrent infections and previous surgeries. Bone grafts were fixed to the bony defect area with microplates and screws or wiring.

After placing the bone graft, dissection to separate the temporalis muscle from the superficial temporal fascia proceeded underneath the superficial temporal fascia through the loose areolar tissue layer, and the remaining capillary anastomosis area at the origin of the temporalis muscle was saved along a margin of about 1 to $2 \mathrm{~cm}$ from the temporal crest. Subsequently, the deep temporal artery was ligated and the muscle was resected above the insertion site, preserving the superficial temporal vessels. After bleeding from the distal margin of the elevated flap was confirmed, the pedicle was isolated and skeletonized as much as necessary to obtain a sufficient rotation arc, until pulsation of the superficial temporal artery was observed (Fig. 1C). Then, the reverse temporalis muscle flap was inserted into the defect site overlying the calvarial bone graft and fixed with absorbable sutures (Fig. 1D). The remaining bi-halved frontal bone flap was replaced and fixed.

\section{Case reports}

Case 1

A 65-year-old male patient was referred with a large mucocele in the frontal and ethmoidal sinus with bony erosion of the frontal bone and supra orbital rim (Fig. 2A). After resection of the mucocele by the neurosurgery team, the supraorbital rim and frontal sinus were reconstructed with a calvarial bone graft, $10 \times 3 \mathrm{~cm}$ in size, which was harvested from the outer cortex of the vertex area (Fig. 2B). The size of the defect at the cranial base was $68 \times 31 \mathrm{~mm}$. Bone grafts in $2 \times 4 \mathrm{~cm}$ pieces were placed for the orbital roof and grafts $7 \times 3 \mathrm{~cm}$ and $2 \times 3 \mathrm{~cm}$ in size were used for the supraorbital rim and frontal bone. The reverse temporalis muscle flap from the left side was elevated and used to

\section{Fig. 1. Intraoperative photos of case 2}

(A) About $2 \mathrm{~cm}$ above the superior temporal line, the pericranium was incised and the temporal muscle was elevated gently to the zygomatic arch. The path of the superficial temporal artery (white line) was confirmed. (B) Resection of the fibrous dysplasia resulted in an anterior to inner cranial base defect, including the right orbital roof. (C) The temporalis muscle was split from the superficial temporal fascia and a continuous running suture (white arrows) was loosely applied to prevent accidental separation between the temporalis muscle and the superficial temporal fascia in the capillary network area. (D) The reverse temporalis muscle flap was inserted into the defect site overlying the calvarial bone graft.
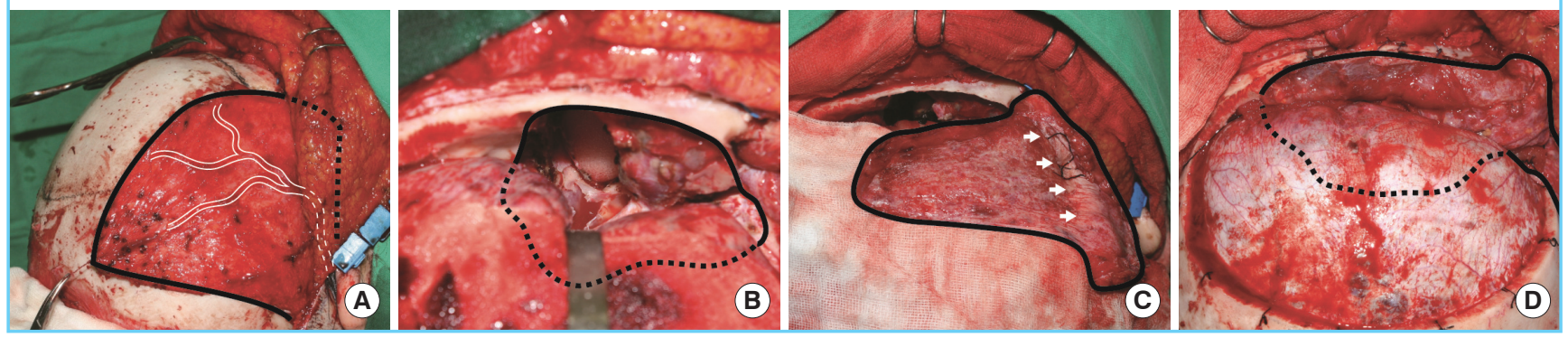

\section{Fig. 2. Pre- and postoperative radiologic studies of case 1}

(A) The mucocele (dotted line) extended to the frontal bone, frontal sinus, ethmoidal sinus, and orbital roof. (B) After resection of the mucocele, the supraorbital rim (arrow) was reconstructed with a calvarial bone graft. (C) Immediate postoperative CT showed the contour of the reverse temporalis muscle flap (dotted line). (D) One year after surgery, CT angiography showed viable flap vascularity (white arrow) and delineation (dotted line).
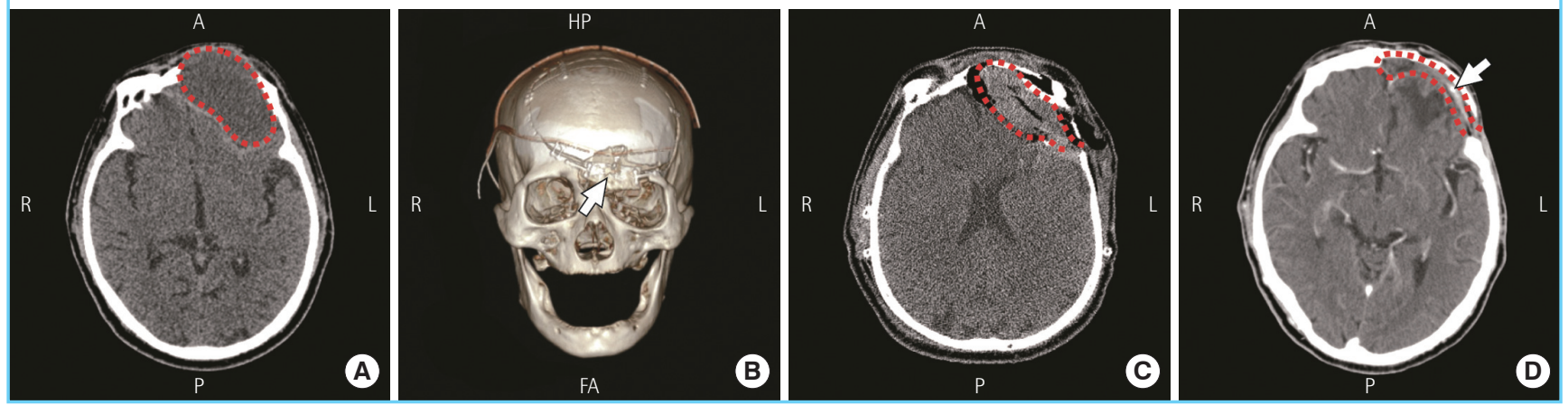


\section{Fig. 3. Pre- and postoperative radiologic studies of case 2}

(A) Extended fibrous dysplasia (dotted line) was invading the optic canal and ethmoidal sinus. (B) The orbital roof was reconstructed with a calvarial bone graft (white arrow). (C) Immediate postoperative CT showed the contour of the reverse temporalis muscle flap (dotted line). (D) On postoperative angiography, retrograde blood flow was confirmed from the superficial temporal artery to the deep temporal artery (white arrow). (E) Eleven months after the operation, CT showed a well-maintained calvarial bone graft with bone induction around the graft (white arrow). This patient underwent augmentation rhinoplasty six months postoperatively.
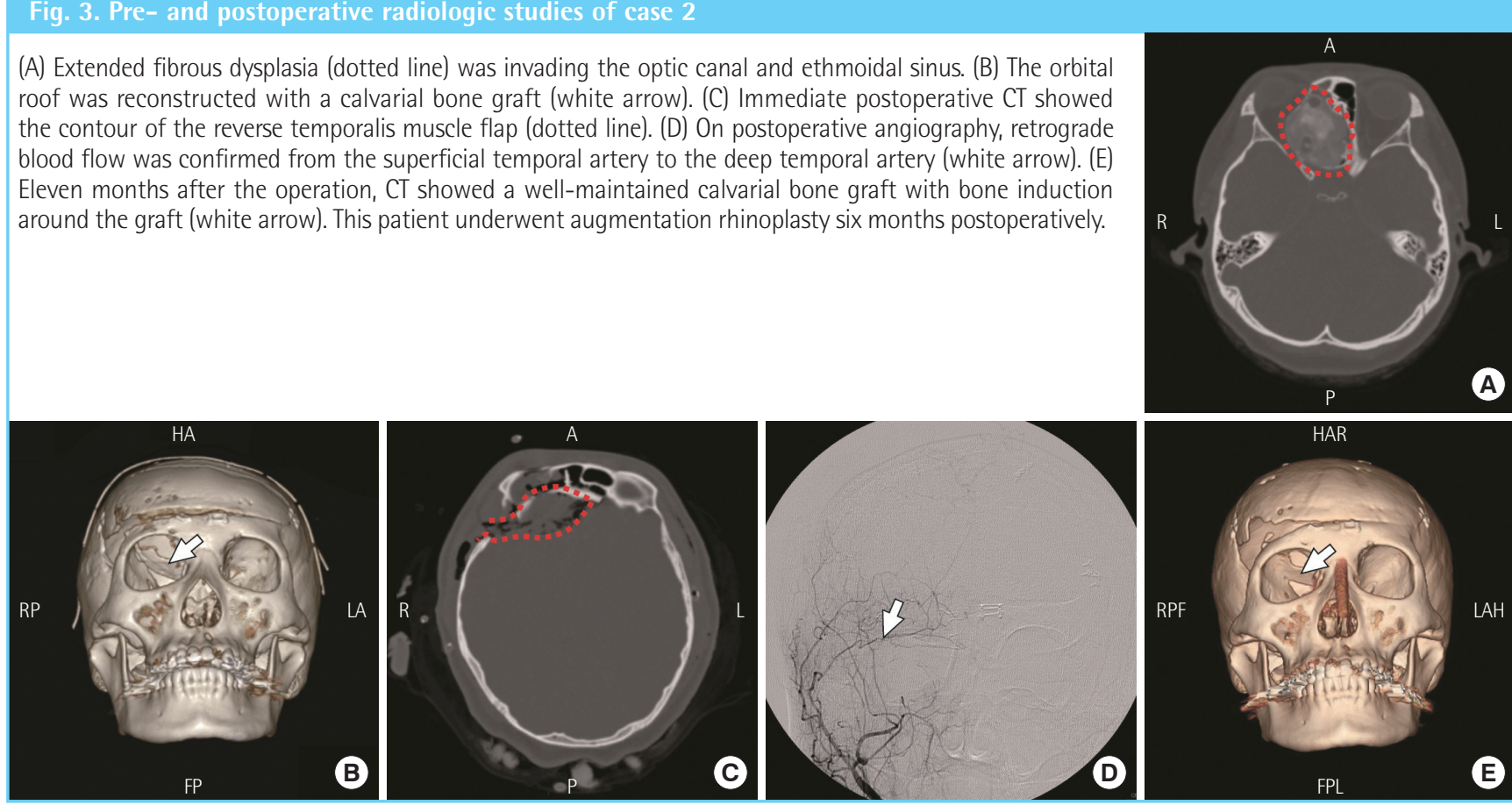

\section{Fig. 4. Postoperative MRI of case 4}

Nine months after surgery, the contour and the delineation of the bilateral reverse temporalis muscle flap were identified (dotted line).
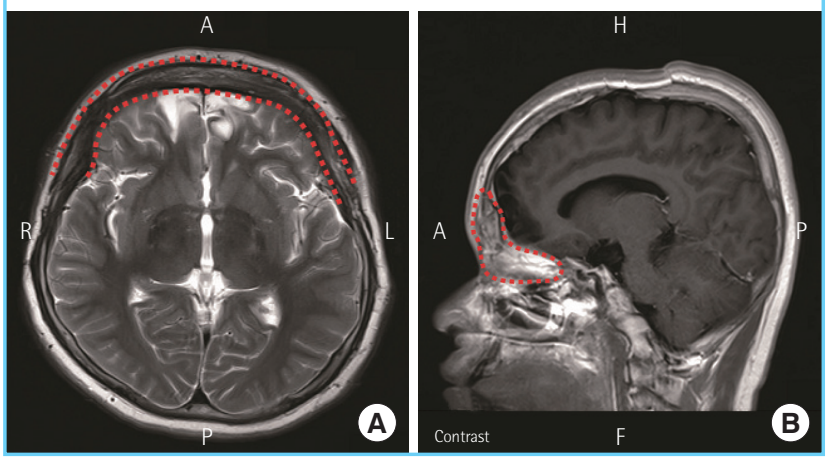

cover the intracranial defect to seal the midline defect (Fig. 2C). There were no complications. One year later, CT angiography was performed and showed stable vascularity and delineation of the flap (Fig. 2D).

\section{Case 2}

A 19-year-old female patient with fibrous dysplasia on the anterior skull base underwent surgery for tumor removal. The tumor was invading the orbital apex, the lesser wing of the sphenoid bone, and the middle cranial fossa, and was pressing on the right optic canal (Fig. 3A). After tumor removal, a large anterior cranial base defect $55 \times 38 \mathrm{~mm}$ in size was noted (Fig. 1B). Calvarial bone was harvested from the inner cortex of a craniotomized frontal bone flap at a size of $12 \times 6 \mathrm{~cm}$ and grafted

onto the anterior cranial fossa, partially covering the orbital roof (Fig. 3B). A $6 \times 4 \mathrm{~cm}$ bone graft for the medial orbital wall and an $8 \times 4 \mathrm{~cm}$ bone graft for the orbital roof were fixed to each other with wiring and to the supraorbital rim with a microplate. Over the bone graft, the right reverse temporalis muscle flap was introduced and fixed with absorbable sutures along the defect margin through drilled holes (Fig. 3C). Two weeks after surgery, conventional angiography showed intact reverse blood flow from the superficial temporal artery to the deep temporal artery (Fig. 3D). After 11 months, stable bone graft survival was confirmed on CT (Fig. 3E).

\section{RESULTS}

The reconstruction was successful in all patients. The average follow-up period was $11.8 \pm 11.12$ months, defined from the date of surgery to the date of the last imaging study. Wellmaintained muscle volume and delineation were confirmed on follow-up CT and MRI. Viable vascularity of the reverse temporalis muscle flap was verified on CT angiography or conventional angiography. All seven flaps showed only minimal atrophic change in bulkiness and patent vasculature to the distal portion of the flaps (Figs. 2D, 3D, 4). The contour and position of the grafted calvarial bone was intact, and showed acceptable union (Fig. 3E).

The mean operation time including the neurosurgical procedure was $8.4 \pm 3.36$ hours, and the mean NICU stay was $1.2 \pm 0.45$ days. There were no significant complications such 
as CSF rhinorrhea, ascending infection, or herniation. Only patients 2 and 3 complained of a postoperative hourglass deformity on the donor site temple. Patient 2 had a dermofat graft and microfat graft placed in the temporal area one year and one and a half years postoperation, respectively.

\section{DISCUSSION}

Large cranial base defects are a cause of major secondary complications such as fatal ascending infection, following persistent nasocranial communication that is intractable to conservative management. Additionally, tension pneumocephalus, seizure, and meningocele may be lethal $[4,5,9]$. Therefore, the ideal coverage option for skull base defects should satisfy the following conditions: 1) watertight sealing to prevent CSF leakage, 2) complete separation between intra- and extra-cranial spaces, 3 ) sufficient bulkiness to fill the dead space, 4) well-vascularized tissue to endure infection, and 5) restoration of a rigid architectural frame to prevent herniation $[2,8,10]$.

Small defects can easily be covered with adjacent tissues. Temporalis muscle flaps, galeal flaps, and pericranial flaps have been widely used. Bone grafts, fat grafts, and bone cement are also versatile options for small cranial base defects [2]. However, large cranial base defects, which are not able to be sufficiently covered with conventional flaps or grafts, can result in serious infections or deformities [2]. Free tissue transfer has been used successfully with a low complication rate to cover large defects $[3,7,10]$. In particular, free flaps are preferred for patients with a history of prior surgery, irradiation, or chemotherapy [10]. Although free flaps are reliable for reconstructing large cranial base defects, donor site morbidity, the requirement of two field approaches, and long surgical time with microanastomosis are limitations of this technique. In addition, some cases of trauma or patients with systemic vascular compromise are not good candidates for free flap. Also, free tissue transfer could be a burden to patients in childhood and adolescence; therefore, regional alternatives should be considered first. Except case 1 , all four of the patients were under 20 years old in this study. Furthermore, case 1 had no reliable recipient vessels nearby the defect.

Since the reverse temporalis muscle flap technique has been introduced, it has been successfully used to cover skull base defects, orbital exenteration defects, and communicated frontal sinus fractures $[6,11,12]$. In addition, anatomical study of the reverse temporalis muscle flap has revealed its reliable retrograde vascular supply system [13]. The temporalis muscle is supplied by the deep temporal artery, but the reverse temporalis muscle flap is supplied by the superficial temporal artery across one angiosome to the deep temporal artery in the retrograde direction [11]. In our cases, bleeding in the distal margin of the flaps was continuously assessed beginning immediately after ligation of the deep temporal artery until the end of pedicle skeletonization.

In a previous study, Kim and Park [6] reported the reverse temporalis muscle flap as a coverage option for blockage of nasocranial communication developed by a mucocele in the frontal sinus. In this study, the combination of autologous split calvarial bone grafting and reverse temporalis muscle flap transposition were performed for the reconstruction of a large inner cranial base defect down to the ethmoidal sinus and orbital structure, which requires rigid frame restoration. Therefore, we needed a wider rotation arc, and that resulted in fan-shaped skeletonization of the superficial temporal artery.

The elevated muscle was fixed to the defect margin with absorbable sutures through drilled holes. Fixation facilitated a more secure watertight seal than is encountered with non-fixed flaps. Because the cranium was reconstructed with bone grafts, complete separation of the cranial spaces was therefore possible. In addition, the temporalis muscle was bulky enough to fill the dead spaces. The unilateral flap is sufficient to reach to the midline, even over the midline, with a maximum length of $20 \mathrm{~cm}$ in adults. However, if the defects which require sufficient bulkiness, extended over the midline, or were too far from the pedicle to be covered by a unilateral muscle, the reverse temporalis muscle was elevated bilaterally. Bilateral flaps can easily contact each other at the midline without tension. The conventional temporalis muscle flap needs an osteotomy on the coronoid process to free the muscle insertion and to obtain a wide rotation arc to reach the defect over the midline [7]. However, the reverse flap provides enough length even with only unilateral elevation.

A defect from previous irradiation or chemotherapy requires highly vascularized tissue. Because this muscle flap has healthy muscular pad endings, it can provide excellent vascularity, not only for tolerating chronic infections, but also for blocking resorption of bone grafts. Furthermore, a calvarial bone graft provides a hard frame for contour and stability, which cannot be obtained with a muscle flap only. Calvarial bone is easy to approach in the same operation field and is less resorptive than a rib bone graft $[14,15]$. Also, it has the advantages of an autogenous tissue such as robustness to infection and cost effectiveness compared to foreign materials such as bone cement or titanium mesh [16]. Even though there were no infections or foreign body reactions in case 3 with hydroxyapatite cement, complications related to alloplastic materials should be considered. Furthermore, the original curvature of the calvarial bone is naturally suited for the orbital roof or cranial base. 
Hanasono et al. [10] published a large retrospective study of skull base reconstruction in 2011. They presented a skull base reconstruction algorithm. They suggested an anterolateral thigh free flap or a rectus abdominis muscle free flap for reconstruction of extended central anterior skull defects and extended lateral defects communicating with the sinuses. Also, in a recent review of the literature, Schmalbach et al. [9] proposed free flap reconstruction as a primary choice for large anterior skull base defects. However, we achieved sustained results with a reverse temporalis muscle flap and calvarial bone graft instead of free flaps for large midline defects. In a study by Hanasono et al. [10], the free flap operation time was 11.2 hours and the pedicle flap operation time was 7.9 hours. In the present study, the total operation time from tumor removal or debridement to scalp closure was 8.4 hours. We think there could be a bias associated with variation in the neurosurgical operation time. Sometimes tumor removal required more than 7 hours. In addition, our study included both uni- and bilateral flap elevations. However, we believe that this technique requires less time than free tissue transfer, which requires an additional operation field for the donor and microanastomosis site.

Intensive care unit stays were also shorter than have been reported in previous studies. As the reverse temporalis muscle flap provides guaranteed vascularity, it does not require close monitoring of microvascular reconstruction. Four patients stayed in the NICU for one night only; however, one patient developed minimal suspicious CSF rhinorrhea. On postoperative day two, this patient was moved to the general ward after confirming the absence of CSF leakage through endoscopy.

In all five cases, successful reconstruction was achieved and there were no serious complications. However, there were hourglass deformities in all five cases in the donor site-temporal depression, which were corrected with simple procedures such as microfat grafting or dermofat grafting under local anesthesia. Hydroxyapatite could also have been used to augment the donor site [1]. Minimal depression at the temple remained, but the patients were satisfied with the final results.

The median follow-up periods were not consistent because the imaging studies were performed according to an unplanned schedule of neurosurgery and plastic surgery visits, and there were follow-up losses. In addition, the follow-up durations in this study varied widely, ranging from 1 to 24 months, and the number of cases was relatively small. Because the purpose of this article was to suggest a new alternative technique that could provide consistent results, we feel that the small number of cases was sufficient.

Complex and large cranial base defects occur due to extensive tumor removal, chronic infection, bony erosion, and trauma.
Curative radical surgeries have become possible owing to advances in reconstruction modalities such as free tissue transfer. However, we achieved excellent results through a combination of autologous split calvarial bone grafting and reverse temporalis muscle flap transposition to cover large cranial base defects requiring only one operation field with a shorter operation time. Calvarial bone grafting provides a three-dimensional architectural frame in which to restore the original cranial structure. The reverse temporalis muscle flap provides vascular supply, a secure seal over free bone grafts, and bulkiness compared with free muscle flaps. Calvarial bone grafting combined with a reverse temporalis muscle flap transposition could be an efficient alternative to free flap reconstruction for complicated large cranial base defects.

\section{REFERENCES}

1. Smith JE, Ducic Y, Adelson RT. Temporalis muscle flap for reconstruction of skull base defects. Head Neck 2010;32: 199-203.

2. Gil Z, Abergel A, Leider-Trejo L, et al. A comprehensive algorithm for anterior skull base reconstruction after oncological resections. Skull Base 2007; 17:25-37.

3. Califano J, Cordeiro PG, Disa JJ, et al. Anterior cranial base reconstruction using free tissue transfer: changing trends. Head Neck 2003;25:89-96.

4. Boyle JO, Shah KC, Shah JP. Craniofacial resection for malignant neoplasms of the skull base: an overview. J Surg Oncol 1998;69:275-84.

5. Gagliardi F, Boari N, Mortini P. Reconstruction techniques in skull base surgery.J Craniofac Surg 2011;22:1015-20.

6. Kim YO, Park BY. Reverse temporalis muscle flap: treatment of large anterior cranial base defect with direct intracranialnasopharyngeal communication. Plast Reconstr Surg 1995; 96:576-84.

7. Clauser L, Curioni C, Spanio S. The use of the temporalis muscle flap in facial and craniofacial reconstructive surgery. A review of 182 cases. J Craniomaxillofac Surg 1995;23: 203-14.

8. Girod A, Boissonnet H, Jouffroy T, et al. Latissimus dorsi free flap reconstruction of anterior skull base defects. J Craniomaxillofac Surg 2012;40:177-9.

9. Schmalbach CE, Webb DE, Weitzel EK. Anterior skull base reconstruction: a review of current techniques. Curr Opin Otolaryngol Head Neck Surg 2010;18:238-43.

10. Hanasono MM, Silva A, Skoracki RJ, et al. Skull base reconstruction: an updated approach. Plast Reconstr Surg 2011; 128:675-86. 
11. Atabey A, Vayvada H, Menderes A, et al. A combined reverse temporalis muscle flap and pericranial flap for reconstruction of an anterior cranial base defect: a case report. Ann Plast Surg 1997;39:190-2.

12. Menderes A, Yilmaz M, Vayvada H, et al. Reverse temporalis muscle flap for the reconstruction of orbital exenteration defects. Ann Plast Surg 2002;48:521-6.

13. Chen CT, Robinson JB Jr, Rohrich RJ, et al. The blood supply of the reverse temporalis muscle flap: anatomic study and clinical implications. Plast Reconstr Surg 1999;103: 1181-8.
14. Inoue A, Satoh S, Sekiguchi K, et al. Cranioplasty with splitthickness calvarial bone. Neurol Med Chir (Tokyo) 1995; 35:804-7.

15. Goodrich JT, Argamaso R, Hall CD. Split-thickness bone grafts in complex craniofacial reconstructions. Pediatr Neurosurg 1992;18:195-201.

16. Rogers GF, Greene AK, Mulliken JB, et al. Exchange cranioplasty using autologous calvarial particulate bone graft effectively repairs large cranial defects. Plast Reconstr Surg 2011;127:1631-42. 


\section{Discussion}

\section{Anterior Cranial Base Reconstruction with a Reverse Temporalis Muscle Flap and Calvarial Bone Graft}

\author{
Ahmad Sukari Halim, Arman Zaharil Mat Saad \\ Reconstructive Sciences Unit, School of Medical Sciences, Universiti Sains Malaysia, \\ Health Campus Universiti Sains Malaysia, Kelantan, Malaysia
}

This article describes a small series of five cases of anterior cranial base reconstruction using a reverse temporalis muscle flap. In four out of the five cases, an autologous split calvarial bone graft was used while in the remaining one case, hydroxyapatite bone cement was used. This one case may be rather confusing to readers. The technique, though it is not a totally new member of the reconstructive armamentarium, it has not been reported widely since it was first described by Kim and Park [1] in 1995 more than one and a half decades ago. Therefore, this series may be worth revisiting, thus highlighting the message again.

As stated by the author(s) of this article, most surgeons would embarked on microsurgical reconstruction for this kind of defect, as evidenced in large series by Cordeiro and Santamaria [2], Califano et al. [3], Chiu et al. [4], and many more. This approach has been a gold standard for many to reconstruct a large base of skull defect.

The temporalis muscle flap has been used in craniofacial reconstruction for more than a century, and one of the earliest reported cases was credited to Golovine, who reported the technique in a French Ophthalmology Journal in 1898 (quoted from Speculand [5]). The anatomy and blood supply of this flap has been described extensively in the literature [6]. Despite being in the locality, being expendable, and lending itself well to craniofacial reconstruction, there are shortcoming of this flap, especially its reach and bulk when the defect is situated more centrally in the midline. Several maneuvers have been attempted to deal with these problems such as resection of the coronoid insertion, and various way of transferring the flap by performing osteotomy or ostectomy.

Kim and Park [1]'s introduction of the reverse temporalis muscle flap had added an extra dimension to the application of the temporalis muscle flap to significantly lengthen the flap's reach. Chen et al. [7] have described the anatomical basis of its blood supply, which originates from the superficial temporal artery instead of the deep temporal arteries via their intercapillaries' connection near the origin of the muscle.

One of the extra advantages of reverse temporalis muscle flap worth mentioning is the possibility of harvesting a vascularized split calvarial bone graft, which may not be possible with regularly used free tissue transfer such as rectus muscle or anterolateral thigh flaps. However, this will add additional technical challenges in the design and inset of the flap. Nevertheless, it would be a more novel approach to this problem. We have published a paper highlighting the unique advantage of the vascularized split calvarial bone graft technique in a child. In our case, the split calvarial bone graft was raised based on the superficial temporal vessel, of which the same vascular pedicle was used in the reverse temporalis muscle flap. A computed tomography scan performed four years after the procedure had shown good graft integration and growth [8]. Other advantages of vascularized calvarial bone graft are greater resistance to infection, no or minimal bone resorption as the osteocytes remain viable and numerous [9]. In the article discussed here, the authors mentioned some of the advantages of calvarial bone graft over other sources of autologous bone graft and synthetic or bio-engineered bone replacement on top of the points mentioned above.

In this series, the authors had mentioned several times that one of the advantage of this technique is that the flap was harvested from one surgical field and which supposedly would have shortened the operative time, as it is a pedicle flap. However, on the other hand, having the flap raised from the same region precluded the two team approach that could have shortened the operative time. Most surgeons would agree that raising free tissue transfer in a second surgical field will allow for a two team approach and most flaps can be completely raised by the time neurosurgical resection is done.

Although the conventional temporalis muscle flap or its reverse modification are proven to be reliable with low complication rates, one of the well-known setbacks of this flap is donor site depression, which may be disfiguring and distressing. Previous reports have advocated temporal implant and even free tissue transfer [10-12]. The authors in this article have used simple techniques like micro-fat grafting and dermo-fat grafting under local anesthesia with acceptable results.

\section{REFERENCES}

1. Kim YO, Park BY. Reverse temporalis muscle flap: treatment of large anterior cranial base defect with direct intracranial-

Copyright ( $) 2012$ The Korean Society of Plastic and Reconstructive Surgeons

This is an Open Access article distributed under the terms of the Creative Commons Attribution Non-Commercial License (http://creativecommons.org/

licenses/by-nc/3.0/) which permits unrestricted non-commercial use, distribution, and reproduction in any medium, provided the original work is properly cited.

www.e-aps.org 
nasopharyngeal communication. Plast Reconstr Surg 1995; 96:576-84.

2. Cordeiro PG, Santamaria E. A classification system and algorithm for reconstruction of maxillectomy and midfacial defects. Plast Reconstr Surg 2000; 105:2331-46.

3. Califano J, Cordeiro PG, Disa JJ, et al. Anterior cranial base reconstruction using free tissue transfer: changing trends. Head Neck 2003;25:89-96.

4. Chiu ES, Kraus D, Bui DT, et al. Anterior and middle cranial fossa skull base reconstruction using microvascular free tissue techniques: surgical complications and functional outcomes. Ann Plast Surg 2008;60:514-20.

5. Speculand B. The origin of the temporalis muscle flap. Br J Oral Maxillofac Surg 1992;30:390-2.

6. Cheung LK. The blood supply of the human temporalis muscle: a vascular corrosion cast study. J Anat 1996;189: 431-8.

7. Chen CT, Robinson JB Jr, Rohrich RJ, et al. The blood supply of the reverse temporalis muscle flap: anatomic study and clinical implications. Plast Reconstr Surg 1999;103: 1181-8.

8. Ali F, Halim AS, Najihah SZ, et al. Combination of vascularized outer-table calvarial bone graft based on the superficial temporal vessels and allomatrix for the repair of an orbito- frontal blow-out fracture in a child. J Craniomaxillofac Surg 2005;33:326-30.

9. Davison SP, Mesbahi AN, Clemens MW, et al. Vascularized calvarial bone flaps and midface reconstruction. Plast Reconstr Surg 2008;122:10e-8e.

10. Baj A, Spotti S, Marelli S, et al. Use of porous polyethylene for correcting defects of temporal region following transposition of temporalis myofascial flap. Acta Otorhinolaryngol Ital 2009;29:265-9.

11. Rapidis AD, Day TA. The use of temporal polyethylene implant after temporalis myofascial flap transposition: clinical and radiographic results from its use in 21 patients. J Oral Maxillofac Surg 2006;64:12-22.

12. Cordeiro PG, Wolfe SA. The temporalis muscle flap revisited on its centennial: advantages, newer uses, and disadvantages. Plast Reconstr Surg 1996;98:980-7.

\footnotetext{
Correspondence: Ahmad Sukari Halim

Reconstructive Sciences Unit, School of Medical Sciences, Universiti Sains Malaysia, Health Campus Universiti Sains Malaysia, 16150 Kubang Kerian, Kelantan, Malaysia

Tel: +609-7676005, Fax: +609-7656532, E-mail: ashalim@kb.usm.my

No potential conflict of interest relevant to this article was reported.

Received: 28 Jun 2012 • Revised: 29 Jun 2012 • Accepted: 30 Jun 2012 pISSN: 2234-6163 • elSSN: 2234-6171

http://dx.doi.org/10.5999/aps.2012.39.4.352 • Arch Plast Surg 2012;39:352-353
} 